\title{
Desenvolvimento das Forças Produtivas e Transformação Social: as Potencialidades Inauguradas pela Produção P2P e Impressoras 3D
}

Development of Productive Forces and Social Transformation: the Potential Inaugurated by P2P Production and 3D Printers

\section{Lucas Rodrigues $^{\mathrm{a}}$}

\begin{abstract}
Resumo: O trabalho aborda a relação entre desenvolvimento das forças produtivas, relações sociais de produção, luta de classes e revolução social. Parte-se do movimento contraditório geral entre desenvolvimento das forças produtivas e relações sociais de produção, expresso na luta de classes. Segundo Marx, para que um novo modo de produção se estabeleça suas condições já devem estar gestadas no seio da antiga sociedade, assim são apontadas as potencialidades de algumas novas tecnologias que permitem, e em certa medida já realizam, novas formas de cooperação, produção e distribuição. Essas tecnologias dizem respeito aos computadores pessoais e à internet, associadas às impressoras $3 \mathrm{D}$.
\end{abstract}

Palavras-chave: Forças Produtivas; Relações Sociais de Produção; Luta de Classes; Internet Classificação JEL: B5

\begin{abstract}
The work addresses the relationship between development of productive forces, social relations of production, class struggle and social revolution. It starts from the general contradictory movement between development of productive forces and social relations of production, expressed in the class struggle. According to Marx, in order for a new mode of production to be established, its conditions must already be developed in the bosom of the old society, so the potentialities of some new technologies that allow, and to some extent already realize, new forms of cooperation, production and distribution are presented. These technologies concern personal computers and the internet associated with $3 \mathrm{D}$ printers.
\end{abstract}

Keywords: Productive Forces; Social Relations of Production; Class Struggle; Internet

\footnotetext{
${ }^{\text {a }}$ Professor do curso de ciências econômicas da Universidade Federal do Sul e Sudeste do Pará (UNIFESSPA).E-mail: lucas.rodrigues@unifesspa.edu.br
} 


\section{Introdução}

The aeroplane and the radio have brought us closer together. The very nature of these inventions cries out for the goodness in men - cries out for universal brotherhood - for the unity of us all (CHAPLIN, 1940).

O homem que dirigia o monstro não lhe podia controlar o barulho, enquanto devassava, efetuando retas, fazendas e mais fazendas. Um aperto num botão faria como que o trator cessasse seu avanço impiedoso, mas o homem que guiava o trator não podia apertar esse botão, porque o homem já era parte integrante do monstro de ferro, porque o espírito desse monstro dominava o homem, orientava-lhe irresistivelmente o cérebro e os músculos (STEINBECK, 1966, p. 41).

Para Marx, a dinâmica da história social é um processo de transformação. Os seres humanos estabelecem relações entre si e formas de organização e cooperação para a reprodução de sua existência, as quais, no entanto, não são fixas. Essas relações se dão de acordo com o grau de desenvolvimento de suas forças produtivas. Conforme essas forças produtivas evoluem e se transformam, entram em contradição com as relações sociais de produção existentes, e com as formas jurídicas de propriedade que expressam essas relações, caracterizando o longo processo de revolução social e transformação. No entanto, o entendimento mecânico desse funcionamento, aliado à associação direta entre forças produtivas e tecnologia, leva muitas vezes a concepções simplistas e distorcidas a respeito de um determinismo tecnológico em Marx. Dentro de tais concepções, o desenvolvimento das forças produtivas em geral, e da tecnologia em específico, aparecem como processo autônomo da dinâmica social, e se impõem sobre a sociedade como uma força exógena, de forma que o papel da luta de classe na transformação da sociedade fica relegado a segundo plano.

O desenvolvimento de Marx a respeito da transformação social em geral, e do modo de produção capitalista em específico, foge, no entanto dessa compreensão mecânica e determinista. A relação entre forças produtivas, relações sociais de produção, luta de classes e revolução social compõem um movimento dinâmico de interação e devem ser entendidas dentro do processo dialético do desenvolvimento histórico. Esse movimento faz com que o processo de transformação social não possa ocorrer em qualquer momento histórico, dentro de um modo de produção, mas dependa de que as contradições que se estabelecem tenham alcançado certo grau de desenvolvimento. Nesse sentido Marx apresenta as duas condições necessárias para a transformação social: que as forças produtivas tenham se desenvolvido de forma que as condições materiais para uma nova sociedade já estejam gestadas; e que exista uma massa revolucionária capaz e disposta a subverter as bases da organização da sociedade vigente.

No entanto, dentro de determinado modo de produção, o desenvolvimento das forças produtivas não atua apenas no sentido de transformação das relações 
sociais de produção existentes. Essas relações sociais de produção também retroagem sobre as forças produtivas, de modo que seu desenvolvimento significa simultaneamente a afirmação de determinado modo de produção. Esse processo é exposto por Marx em sua descrição sobre a passagem do modo de produção feudal para o capitalista. Quando em emergência, apesar da existência das relações sociais de produção que o caracterizam, as forças produtivas vigentes ainda barravam seu funcionamento pleno. Essas vão se transformando até culminarem com a grande fábrica mecanizada, a qual representa as forças produtivas em sua forma desenvolvida dentro do modo de produção capitalista.

Nesse sentido, o presente trabalho objetiva tratar, a partir de Marx, a relação entre desenvolvimento das forças produtivas, relações sociais de produção, luta de classes e revolução social. Isso é abordado tanto em sua forma geral quanto em sua forma específica dentro do modo de produção capitalista. Uma segunda importante questão diz respeito à necessidade exposta por Marx de que, para que um novo modo de produção substitua o anterior, as novas relações sociais de produção já devem estar gestadas no seio da velha sociedade. Com o objetivo de abordar essa questão são investigadas, as potencialidades inauguradas por algumas novas tecnologias, em especial em relação às mudanças na organização do processo de trabalho, cooperação, produção e distribuição possibilitadas e em alguma medida já realizadas por elas. Essas novas tecnologias referem-se principalmente às formas colaborativas de produção através dos computadores pessoais e da internet, associadas às impressoras $3 \mathrm{D}$.

\section{A Dupla Natureza do Desenvolvimento das Forças Produtivas}

Tratar sobre a relação entre desenvolvimento das forças produtivas e transformação social em Marx não é uma tarefa simples. O desafio se coloca dado que sua concepção foge de qualquer relação mecânica de causa ou efeito, ou relação direta de determinante e determinado. Se por um lado é marcante a contradição que se estabelece entre o desenvolvimento das forças produtivas e as relações sociais de produção - e a forma jurídica de propriedade nas quais essas relações se expressam -, por outro lado também nota-se que as relações sociais de produção, dentro de determinado modo de produção, não encontram em seu início as forças produtivas em sua forma plenamente adequada e, portanto influem sobre seu desenvolvimento. Como exemplo Marx descreve o próprio desenvolvimento do modo de produção capitalista. As forças produtivas existentes quando de sua emergência ainda se baseavam naquelas da oficina e da manufatura, as quais também se encontravam no modo feudal de produção. Apenas mais tarde se desenvolve a moderna fábrica mecanizada, a qual contém as forças produtivas que condizem plenamente com as relações sociais capitalistas de produção. Ainda, a contradição entre as forças produtivas e as relações sociais de produção se expressa concretamente e constitui 
"o fundamento material da luta de classes" (GERMER, 2009, p. 77), de modo que esse aspecto também deve ser considerado. A presente investigação parte, assim, da forma geral como essa contradição opera, para posteriormente apontar para sua forma específica dentro do modo de produção capitalista.

Marx (2008, p. 47-48), ao resumir sua concepção geral sobre a relação contraditória entre desenvolvimento das forças produtivas e relações sociais de produção, coloca que:

O resultado geral a que cheguei e que, uma vez obtido, serviu-me de guia para meus estudos, pode ser formulado, resumidamente, assim: na produção social da própria existência, os homens entram em relações determinadas, necessárias, independentes de sua vontade; essas relações de produção correspondem a um grau determinado de desenvolvimento de suas forças produtivas materiais. A totalidade dessas relações de produção constitui a estrutura econômica da sociedade, a base real sobre a qual se eleva uma superestrutura jurídica e política e à qual correspondem formas sociais determinadas de consciência. $\mathrm{O}$ modo de produção da vida material condiciona o processo de vida social, política e intelectual [...]. Em uma certa etapa de seu desenvolvimento, as forças produtivas materiais da sociedade entram em contradição com as relações de produção existentes, ou, o que não é mais que sua expressão jurídica, com as relações de propriedade no seio das quais elas se haviam desenvolvido até então. De formas evolutivas das forças produtivas que eram, essas relações convertem-se em entraves. Abre-se, então, uma época de revolução social. A transformação que se produziu na base econômica transforma mais ou menos lenta ou rapidamente toda a colossal superestrutura [...]. Uma sociedade jamais desaparece antes que estejam desenvolvidas todas as forças produtivas que possa conter, e as relações de produção novas e superiores não tomam jamais seu lugar antes que as condições materiais de existência dessas relações tenham sido incubadas no próprio seio da velha sociedade.

Essa longa citação de Marx suscita algumas questões importantes. Em primeiro lugar, torna-se necessário esclarecer o significado mais amplo, em Marx, a respeito das forças produtivas. A segunda questão diz respeito ao motor do processo de transformação dessas forças. A terceira refere-se à direção ou ao sentido dessa transformação. A quarta questão é sobre a concepção de revolução social.

Existe, dentre os autores que consideram Marx um determinista tecnológico, uma associação direta entre tecnologia e forças produtivas (MACKENZIE, 1984, p. 477). Para esse grupo, desenvolvimento das forças produtivas e desenvolvimento tecnológico são tratados como sinônimos, e dessa forma o desenvolvimento tecnológico é considerado como a força motora da mudança social. Essa associação direta, no entanto, não pode ser atribuída a Marx. A tecnologia, no sentido dos instrumentos que medeiam "a relação entre o homem e o mundo exterior, material" (ROSENBERG, 2006, p. 74), responde apenas por parte das forças produtivas de uma sociedade e não por sua totalidade (LUKÁCS, 1966, p. 29). Germer (2009, p. 80) define forças produtivas de forma mais ampla, como "[o] conjunto dos materiais naturais que transforma para seu uso, dos instrumentos e demais materiais e instalações que o auxiliam no trabalho, e do próprio conhecimento acumulado e da aptidão adquirida para o trabalho". Marx e Engels (2006, p. 55), por sua vez, apontam 
que mesmo as diferentes formas de cooperação social ${ }^{1}$ constituem em si uma força produtiva. Segundo eles "um modo de produção ou uma determinada fase industrial estão sempre ligados a uma determinada forma de cooperação e a uma fase social determinada, e que essa forma de cooperação é, em si própria, uma força produtiva". Nesse sentido, quando se investiga a contradição entre as forças produtivas e as relações sociais de produção essa não deve ser entendida considerando-se apenas o conjunto do aparato técnico de uma sociedade. Tal contradição se estabelece entre as forças produtivas em sua definição mais ampla. Conjuntamente, quando Marx afirma que "as relações de produção novas e superiores não tomam jamais seu lugar antes que as condições materiais de existência dessas relações tenham sido incubadas no próprio seio da velha sociedade", ele não se refere apenas à tecnologia como condição material necessária. Todo o corpo de conhecimento, instalações, matérias e mesmo formas de cooperação social devem existir, ainda que em sua forma embrionária, as quais possibilitem uma nova relação social de produção.

A segunda questão referida diz respeito ao motor do desenvolvimento das forças produtivas. Como bem salienta Marx na passagem acima, os seres humanos entram em relações determinadas em seu processo histórico, as quais refletem e correspondem ao nível de desenvolvimento de suas forças produtivas. Essas relações, por sua vez, aparecem como independentes de sua vontade ${ }^{2}$. A ação prática cotidiana dos indivíduos não os revela, portanto, as leis de movimento da sociedade, no entanto "o fato de o ser humano não ter consciência das leis de movimento da sociedade, que ele mesmo gera com sua ação, não imped[e] que a sociedade se transform[e] continuamente" (GERMER, 2009, p. 79). Na vida cotidiana os

\footnotetext{
${ }^{1}$ Nessa passagem Marx e Engels não se referem unicamente à cooperação na produção material de bens e serviços, mas sim no sentido mais amplo de cooperação social, a qual assume diferentes formas nos distintos modos de produção. "A produção da vida, seja da própria vida pelo trabalho, seja a de outros, pela procriação, nos aparece a partir de agora como dupla relação: de um lado, como relação natural, de outro, como relação social - social no sentido em que se compreende por isso a cooperação de vários indivíduos, em quaisquer condições, modo e finalidade. De onde se segue que um modo de produção ou uma determinada fase industrial estão sempre ligados a uma determinada forma de cooperação e a uma fase social determinada, e que essa forma de cooperação é, em si própria, uma força produtiva; decorre disso que o conjunto das forças produtivas acessíveis aos homens condiciona o estado social e que, assim, a 'história dos homens' deve ser estudada e elaborada sempre em conexão com a história da indústria e do intercâmbio" (MARX; ENGELS, 2006, p. 55).

2 "A atitude primordial e imediata do homem, em face da realidade, não é a de um abstrato sujeito cognoscente, de uma mente pensante que examina a realidade especulativamente, porém, a de um ser que age objetiva e praticamente, de um indivíduo histórico que exerce a sua atividade prática no trato com a natureza e com os outros homens, tendo em vista a consecução dos próprios fins e interesses, dentro de um determinado conjunto de relações sociais. [...]. No trato prático-utilitário com as coisas - em que a realidade se revela como mundo dos meios, fins, instrumentos, exigências e esforços para satisfazer a estas - o indivíduo "em situação" cria suas próprias representações das coisas e elabora todo um sistema correlativo de noções que capta e fixa o aspecto fenomênico da realidade” (KOSIK, 2011, p. 13-14).
} 
indivíduos, em sociedade se defrontam com necessidades imediatas, as quais devem ser supridas segundo o grau de desenvolvimento de suas forças produtivas e dentro das relações sociais de produção subjacentes a ela. O modo de satisfazer essas necessidades, em qualquer tempo e espaço, se dá através de sua atividade práticosensível, ou seja, pelo seu processo de trabalho em sentido geral ${ }^{3}$. É através dessa atividade que o ser humano desenvolve sua consciência e conhecimento e assim transforma, de maneira mais ou menos acelerada, as formas e os instrumentos de sua ação. O processo de trabalho é, portanto, não apenas processo de repetição, mas também de conhecimento e transformação. Segundo Marx (1996, p. 297):

Antes de tudo, o trabalho é um processo entre o homem e a Natureza, um processo em que o homem, por sua própria ação, media, regula e controla seu metabolismo com a Natureza. Ele mesmo se defronta com a matéria natural como uma força natural. Ele põe em movimento as forças naturais pertencentes a sua corporalidade, braços e pernas, cabeça e mão, a fim de apropriar-se da matéria natural numa forma útil para sua própria vida. Ao atuar, por meio desse movimento, sobre a Natureza externa a ele e ao modificá-la, ele modifica, ao mesmo tempo, sua própria natureza.

No processo de trabalho, portanto, o homem se apropria da natureza, de suas propriedades e de seu funcionamento e nesse sentido, transforma-a em algo para si. Ao agir sobre ela e conhecê-la ${ }^{4}$, ele também modifica as formas e os meios dessa ação, é através do trabalho como motor do processo de transformação das forças produtivas que o ser humano transforma a si mesmo e a sua vida em sociedade. Todo processo de trabalho não é, no entanto, meramente atividade em seu sentido individual, mas dado o caráter social da vida humana, o trabalho como meio direto de satisfação das necessidades também necessita de determinada forma de divisão social. Essa divisão se modifica no processo contínuo da atividade humana. Segundo Marx e Engels (2006, p. 46), "cada nova fase da divisão do trabalho determina igualmente as relações entre os indivíduos no que diz respeito ao material, ao instrumento e ao produto do trabalho", de modo que a divisão do trabalho também permite determinada forma de propriedade.

\footnotetext{
3 "Se a sociedade humana está em contínua transformação, sem que esta decorra da ação intencional do ser humano, isso só pode ocorrer se o ser humano for forçado a realizar continuamente um tipo de atividade prática da qual resulta, involuntariamente, a criação das condições necessárias à transformação social. Para que essa atividade seja obrigatória e ininterrupta, deve decorrer de uma necessidade que opera ininterruptamente e que independe da vontade do ser humano. Essa atividade prática é o trabalho, e é imperiosa porque é indispensável à reprodução material da vida humana." (GERMER, 2009, p. 8o)

4 Tal afirmação não significa que na atividade prática do ser humano com a natureza esta se revele a ele em sua totalidade. Significa apenas que "conhecimento não é contemplação" (KOSIK, 2011, p. 28), e que é somente através da atividade prática de transformação e domínio da natureza que o ser humano pode desvendar seu funcionamento.
} 
Diferentemente do que certas posições deterministas propõem ${ }^{5}$, o desenvolvimento das forças produtivas, para Marx, não é gerado por forças e leis de movimento autônomas ao processo social. Pelo contrário, é a atividade contínua e ininterrupta do ser humano em sociedade, a qual gera as condições materiais de vida que são transmitidas e transformadas pelas sucessivas gerações, que move todo esse desenvolvimento.

A terceira questão levantada, nesse sentido, pode ser formulada da seguinte maneira: Dado que o trabalho é o fundamento do desenvolvimento das forças produtivas, e que estas são transmitidas e transformadas entre as sucessivas gerações, existe uma direção progressiva, no sentido de avanço, no desenvolvimento dessas forças? Germer (2009, p. 81) responde que, abstraindo desse desenvolvimento situações históricas específicas e contingentes, tal caráter progressivo se verifica. Esse caráter se dá pela própria natureza do trabalho social, em que o aprofundamento do conhecimento resulta em técnicas e mecanismos mais produtivos, os quais levam ao abandono daqueles mais antigos. Isso não significa, no entanto, que concretamente as sociedades não podem sofrer reversões, ou que o processo social será sempre caracterizado por um sucessivo aumento da produtividade. Guerras, desastres naturais, escassez de bens necessários etc. ${ }^{6}$, podem resultar em uma reversão no aparelho produtivo e no conhecimento gerado e transmitido entre gerações. Essa interpretação se verifica em Marx e Engels (2006, p. 88):

Depende tão somente da extensão se as forças produtivas alcançadas em uma região (principalmente as invenções) são aproveitadas ou não para o desenvolvimento posterior. Quando ainda não existe relação de comércio para além dos círculos mais próximos, cada invenção deve ser feita em separado em cada região, e meros acasos, tais como a invasão dos povos bárbaros e até mesmo guerras habituais são o que basta para fazer com que um país com forças produtivas e necessidades desenvolvidas tenha de recomeçar a partir do zero [...]. A permanência das forças produtivas adquiridas só é assegurada com o comércio mundial que tem por base a grande indústria, quando todas as nações são conduzidas à disputa da concorrência.

A tendência à formação do mercado mundial dentro do modo de produção capitalista, o qual lança dentro da dinâmica concorrencial os capitais das distintas nações, também eleva a essa esfera global os processos de produção e circulação. As forças produtivas e as relações de produção subjacentes a elas deixam de ter um caráter local, ou de se reproduzirem apenas localmente, para se imporem como

\footnotetext{
5 Dentre os autores que mantém uma posição determinista da tecnologia como motor da dinâmica social Mackenzie (1984, p. 474) destaca: Hansen (1921); Heilbroner (1967) e; Burns (1969).

${ }^{6}$ Landes (2005, p. 33) atribui, por exemplo, às sucessivas invasões, disputas e conquistas no mundo muçulmano como um dos fatores que contribuiu para a perda de dinamismo tecnológico e científico nesses locais, dado que a destruição da base material e mesmo a imposição de novas culturas e novos costumes limitava a transmissão dos avanços para as gerações seguintes.
} 
relações de produção dominantes em todas as partes. Esse processo garante com mais segurança a permanência e a transmissão das forças produtivas e do conhecimento para as sucessivas gerações. Em comparação com os modos de produção anteriores, no modo de produção capitalista essa tendência de avanço e transmissão das forças produtivas se expressa mais livremente, ainda que não em sua máxima potência, dado os limites impostos pelo caráter privado da apropriação. A quarta questão diz respeito ao fato de que, para Marx, a existência de forças produtivas que permitam uma transformação nas relações sociais de produção e na estrutura econômica da sociedade é condição necessária, mas não suficiente para tanto. Conjuntamente, é necessária a existência de uma massa revolucionária capaz e disposta a subverter sua condição material de existência e de reprodução da vida social. Segundo Marx e Engels (2006, p. 66):

Essas condições de existência, que as várias gerações encontram já prontas, decidem também se as convulsões revolucionárias que periodicamente se repetem na história serão ou não fortes o suficiente para subverter as bases do que já existe. Os elementos materiais para a subversão total são, por um lado, as forças produtivas existentes e, por outro, a formação de uma massa revolucionária que se revolte não só contra as condições particulares da sociedade atual, mas também contra a própria 'produção da vida' vigente, contra a 'atividade total' sobre a qual se fundamenta. Caso não existam tais elementos materiais, então, no que se refere ao desenvolvimento prático, é totalmente indiferente que a ideia dessa subversão já tenha sido proclamada uma centena de vezes, como mostra a história do comunismo.

Essa massa revolucionária, condição imprescindível da transformação social, surge como expressão da contradição entre as forças produtivas e as relações de produção. A forma assumida pela luta de classes que acompanha o processo de desenvolvimento dessa contradição se dá preferencialmente sobre a apropriação do produto da sociedade e, portanto, em oposição à forma jurídica de propriedade subjacente a determinada relação social de produção7. Segundo Germer (2009, p. 86), o advento da propriedade privada impõe um fator de rigidez no processo de transformação social. Isso se dá, visto que com a propriedade privada as relações

\footnotetext{
7 Tratar sobre a forma assumida pela luta de classes foge do escopo desse trabalho, no entanto, algumas considerações devem ser feitas. Marx e Engels (2006, p. 6o-61) colocam que, na vida em sociedade, se estabelece uma contradição entre interesses particulares e coletivos e que o interesse coletivo toma uma forma na qualidade de Estado. Quando a sociedade evolui para uma divisão em classes, "condicionadas pela divisão do trabalho [...] e entre as quais há uma que domina a outra", esse interesse coletivo materializado no Estado, em suas instituições e em sua base jurídica, passa a expressar o interesse dessa classe dominante. Dessa forma, "segue-se que todas as lutas no âmbito do Estado, isto é, a luta entre democracia, aristocracia e monarquia, a luta pelo direito de voto etc., são apenas as maneiras ilusórias nas quais se desenvolvem as lutas reais entre diferentes classes. Segue-se também que toda classe que aspira à dominação, mesmo que essa dominação, como é o caso do proletariado, exija a superação de toda forma antiga de propriedade e de dominação em geral, deve primeiro conquistar o poder político, para apresentar seu interesse como interesse geral, ao que está obrigada no primeiro momento."
} 
sociais de produção se manifestam não mais apenas como o processo concreto de relação dos indivíduos na produção, mas também sob uma forma jurídica de "leis nas quais são codificadas os direitos dos proprietários e os deveres dos não proprietários". Essa dupla forma de expressão das relações sociais de produção faz com que, enquanto se processa a dinâmica conjunta de transformação das forças produtivas e das relações de produção, a forma jurídica se mantenha mais ou menos inalterada. Para Germer (2006, p. 86) o desenvolvimento desse processo pode ser sintetizado da seguinte forma:

[A]s leis que definem os direitos de propriedade baseados nas relações de produção vigentes não sofrem um processo de evolução espontâneo e progressivo, como ocorre com as forças produtivas, mas só podem ser alteradas por mudanças da ordem jurídica, que afetam os direitos estabelecidos e dependem, por essa razão, da correlação de forças entre os diferentes pleiteantes de direitos, ou seja, dependem da luta de classes. Consequentemente, a forma jurídica da propriedade permanece inalterada, no essencial, durante o período histórico coberto por um modo de produção. Mas a forma material da apropriação, que a forma jurídica da propriedade expressa, continua evoluindo, uma vez que ela representa a forma real das relações entre os indivíduos, e estas se alteram com o desenvolvimento das forças produtivas, cujo nível não está fixado em lei e depende do desenvolvimento científico e tecnológico progressivo. Estabelece-se, portanto, uma contradição entre as relações materiais de produção e sua expressão jurídica na forma da propriedade.

Esse processo de disputa entre as classes, que pode culminar com uma mudança na forma jurídica de propriedade e, em última instância, de toda estrutura econômica da sociedade, depende que a contradição entre forças produtivas e relações sociais de produção alcance um nível em que possa se expressar em uma classe revolucionária. Não depende, entretanto, que as novas relações de produção e as novas formas jurídicas de propriedade subjacentes a ela já existam em sua forma mais desenvolvida, ou que já sejam as relações de produção dominantes. Elas existem nesses períodos apenas em sua forma embrionária, e é o resultado da luta de classes que definirá seu desenvolvimento futuro. Nesse aspecto, Germer (2006, p.87) faz uma importante diferenciação entre "a revolução social como processo e a revolução política como momento decisivo". A primeira aparece como processo contínuo e longo, que se inicia logo a contradição entre as forças produtivas e as relações sociais de produção começa a se desenvolver dentro de determinado modo de produção. A segunda é o momento culminante da revolução social, quando a classe revolucionária depõe a classe até então dominante e conquista o poder de Estado. É a partir desse momento que as novas relações sociais de produção podem se estabelecer como relações dominantes, e estas, por sua vez, podem retroagir sobre o próprio desenvolvimento futuro das forças produtivas. Conforme esse processo se fixa, são rompidas as barreiras que impediam que as forças produtivas e as relações de produção se desenvolvessem em acordo uma com a outra. O desenvolvimento futuro das forças produtivas irá superar paulatinamente aquelas que caracterizavam o período anterior e que se tornaram incondizentes com as novas relações sociais de 
produção, ou que impediam sua generalização. Germer (2006, p. 86) afirma nesse sentido que, "[n]o apogeu de um modo de produção há consonância entre o nível de desenvolvimento das forças produtivas, as relações de produção que lhe correspondem e sua expressão nas leis".

\section{Forças Produtivas e Relações Sociais de Produção no Modo de Produção Capitalista}

Esse processo até aqui tratado de maneira bastante abstrata e geral assume diferentes formas nos distintos modos de produção e em suas transformações. No período feudal, a ascensão do comércio e sua expansão geográfica, o fortalecimento da vida urbana e de suas formas de cooperação, o aparato técnico e a organização da produção; todas essas forças produtivas que vinham num processo ascendente de desenvolvimento passam a gestar uma nova relação social de produção. Essa inicialmente se caracterizava pelo domínio do capital comercial sobre as corporações de ofício, o que impunha que as demandas e o controle sobre a produção fossem realizados dentro de novas relações mediando o processo produtivo. Essas novas relações de produção não mais se expressavam na forma jurídica de propriedade na qual a nobreza rural se baseava. Por sua vez, a classe burguesa ascendente, que paulatinamente passa a dominar tanto o comércio quanto a produção, se vê em oposição a essa forma jurídica de propriedade e consequentemente à classe que a expressava materialmente. $\mathrm{O}$ longo processo de revolução social culmina com a revolução política, a qual se dá em distintos locais e em diferentes períodos, mas que resulta em uma nova relação de propriedade e uma nova classe dominante que impõe sua vontade como vontade geral. A partir daí as forças produtivas podem se desenvolver mais livremente, não sendo limitadas por relações sociais de produção e jurídicas incondizentes com elas. Os limites que as corporações de ofício e o aparato técnico existente impunham ao desenvolvimento pleno desse novo modo de produção também vão sendo superados, até o ponto em que as forças produtivas alcançam sua forma plena na grande fábrica mecanizada. Estas, no entanto dão origem a novas formas de contradição e a uma nova classe capaz de se transformar em massa revolucionária.

O desenvolvimento das forças produtivas dentro de um modo de produção tem, portanto, um duplo significado ou ação. Por um lado, ele se dá de acordo com as relações sociais de produção e sua forma jurídica de propriedade e, nesse sentido, afirma-as e as aprofunda, por outro lado ele entra em contradição com estas e se expressa em uma classe capaz de transformar toda estrutura econômica da sociedade. Esses dois movimentos não são momentos distintos e podem ser separados apenas analiticamente. Constituem, porém, a própria natureza do desenvolvimento das forças produtivas dentro de um modo de produção. 
Marx, em sua análise sobre o modo de produção capitalista, apresenta como esse processo se desenvolve na passagem da manufatura para a grande fábrica mecanizada. Apenas quando as forças produtivas atingem essa forma, quando o meio de trabalho é revolucionado e passa a sujeitar o trabalhador, é que se atinge a consonância entre o nível de desenvolvimento das forças produtivas e as relações sociais de produção capitalistas. Por um lado, portanto, o desenvolvimento das forças produtivas no modo de produção capitalista resulta no aumento da exploração da classe trabalhadora, tanto pela via relativa quanto pela absoluta; acelera o processo de concentração do capital e a separação dos trabalhadores e dos meios de produção; leva à alienação do trabalhador em relação ao produto de seu trabalho. Simultaneamente, quando as forças produtivas atingem tal estágio e seguem seu processo de desenvolvimento, também se estabelece uma contradição a qual se expressa em uma massa proletária capaz de desencadear um processo revolucionário. A extrema divisão social do trabalho; a capacidade de conhecimento que essa divisão permite e realiza; a impossibilidade de reprodução da vida localmente; a formação de uma classe proletária global; todas essas formas que as forças produtivas assumem entram em choque com o caráter privado da apropriação capitalista, o que caracteriza o longo processo de revolução social.

$\mathrm{O}$ ponto de partida a ser considerado na investigação sobre o desenvolvimento das forças produtivas no modo de produção capitalista é o processo de valorização. Segundo Mackenzie (1984, p. 481), o processo de valorização é a forma social do processo de produção específico ao capitalismo, o qual sujeita e se impõe sobre o processo de trabalho. A finalidade última da produção deixa de ser a criação de valores de uso para ser a criação de valor e valorização do capital. Esse processo de valorização se dá dentro de uma luta concorrencial contínua, o que exige o revolucionamento permanente dos instrumentos, das formas de organização da produção e das próprias mercadorias resultantes desse processo. Segundo Shaikh (1991, p. 54),

La fuerza que da impulso a la actividad capitalista es el deseo de ganancias, lo que obliga a cada capitalista individual a dar la batalla en dos frentes: en el proceso de trabajo, contra los trabajadores durante la producción de plusvalía, y en el proceso de circulación, contra otros capitalistas, durante la realización de la plusvalía en forma de ganancias. En el enfrentamiento con el trabajo, la mecanización aparece como la forma más eficaz para incrementar la producción de plusvalía, mientras en el enfrentamiento con otros capitalistas, la reducción de los costos unitarios de producción por unidad (precios de costo unitarios) surge como principal arma para la competencia.

No processo de valorização do capital o capitalista individual luta, portanto, nessas duas frentes. Por um lado, contra a classe trabalhadora, buscando extrair o máximo de trabalho dentro de determinada jornada, por outro contra os demais capitalistas na realização da produção e na apropriação da mais-valia. O meio principal para atingir ambos objetivos se dá através do aperfeiçoamento tanto das 
técnicas como da organização e controle da produção e da valorização ${ }^{8}$. Marx, ao descrever a passagem da manufatura para a grande fábrica mecanizada indica que, apesar das relações capitalistas de produção já existirem na primeira, a valorização do capital ainda se via bastante limitada devido à posição central do trabalhador no processo produtivo. Mesmo que nessa forma inicial da produção capitalista o trabalhador já existisse separado dos meios de produção, e a oposição entre capital e trabalho já operasse, a produção final e seu ritmo ainda dependiam do conhecimento e da habilidade do trabalhador. Apenas com o desenvolvimento da grande fábrica e da maquinaria é que se completa a subordinação do trabalho ao capital e ao ritmo de trabalho, habilidade e conhecimento deixam de ser fatores pertencentes aos trabalhadores para tornarem-se imposições da maquinaria e das técnicas de organização e controle sobre eles. Marx (1996, p. 28), utilizando extensos relatórios e depoimentos, descreve assim os efeitos imediatos da produção mecanizada sobre o trabalhador, sendo estes a incorporação do trabalho infantil e feminino, o prolongamento da jornada de trabalho e a intensificação do trabalho. Também relata como o desenvolvimento da maquinaria serviu para minar a organização da classe trabalhadora e suas revoltas e greves (MARX, 1996, p. 66). Tal efeito da maquinaria, no entanto, não decorre dela em si, mas sim de sua utilização capitalista9 ${ }^{9}$.

O desenvolvimento das forças produtivas dentro do modo de produção capitalista segue, assim, uma direção no sentido de afirmá-lo e possibilitar seu aprofundamento através do aumento da exploração e da alienação do trabalhador e consequentemente da produção de mais-valia. Para Marx e Engels (2006, p. 103), "[o] trabalho, única conexão que os indivíduos ainda mantêm com as forças produtivas e com sua própria existência, perd[e] para eles toda a aparência de atividade de si mesmos e só conserva sua vida atrofiando-a”, esse efeito mais aparente e imediato

\footnotetext{
8 Para uma análise sobre as mudanças técnicas e organizacionais para o controle do processo de trabalho ver Chandler (1977); sobre o processo de valorização ver Bryer (2006).

9 Segundo Marx (1996, p. 73): “As contradições e os antagonismos inseparáveis da utilização capitalista da maquinaria não existem porque decorrem da própria maquinaria, mas de sua utilização capitalista! Já que, portanto, considerada em si, a maquinaria encurta o tempo de trabalho, enquanto utilizada como capital aumenta a jornada de trabalho; em si, facilita o trabalho, utilizada como capital aumenta sua intensidade; em si, é uma vitória do homem sobre a força da Natureza, utilizada como capital submete o homem por meio da força da Natureza; em si, aumenta a riqueza do produtor, utilizada como capital o pauperiza etc." Para Mackenzie (1984, p. 501), isso não significa, no entanto, que a tecnologia é neutra; segundo o autor: "In any society, the design of production technology will reflect the need for that technology to be part of a labor process that is a functioning whole. This implies obvious physical constraints: thus the instruments of production must be compatible with the raw material available. But it also implies social constraints. The labor process in a capitalist society must function effectively not simply as a material process of production, but as a valorization process. Production technology will thus be designed with a view to ensuring successful valorization, and valorization will typically not simply be a matter of "profit maximizing" but will involve the creation and maintenance of desired social relations."
} 
faz com que, muitas vezes, o trabalhador se revolte contra o próprio meio de trabalho.

Esse, no entanto, não é o único efeito do desenvolvimento das forças produtivas em geral e da maquinaria em específico dentro do modo de produção capitalista. Segundo Marx (1996, p. 20), uma característica fundamental da produção mecanizada é o fato de que "[a] maquinaria [...] só funciona com base no trabalho imediatamente socializado ou coletivo. O caráter coletivo do processo de produção torna-se agora, portanto, uma necessidade técnica ditada pela natureza do próprio meio de trabalho". O desenvolvimento desse processo faz com que a produção e a distribuição assumam crescentemente um caráter global. Essa extensa socialização da produção e divisão do trabalho baseiam-se, por sua vez, no conhecimento técnico e científico e possibilitam seu aprofundamento, os quais abrem a possibilidade de formas alternativas tanto de produção quanto de distribuição ${ }^{10}$. Aliado a isso, o desenvolvimento das forças produtivas impulsionado pela concorrência entre capitalistas também desencadeia um processo amplo de centralização de capital. Esses efeitos estão na base das contradições que se estabelecem entre as forças produtivas e as relações sociais de produção dentro do modo de produção capitalista. Segundo Marx (1996, p. 380-381):

Essa expropriação se faz por meio do jogo das leis imanentes da própria produção capitalista, por meio da centralização dos capitais. Cada capitalista mata muitos outros. Paralelamente a essa centralização ou à expropriação de muitos outros capitalistas por poucos desenvolvese a forma cooperativa do processo de trabalho em escala sempre crescente, a aplicação técnica consciente da ciência, a exploração planejada da terra, a transformação dos meios de trabalho em meios de trabalho utilizáveis apenas coletivamente, a economia de todos os meios de produção mediante uso como meios de produção de um trabalho social combinado, o entrelaçamento de todos os povos na rede do mercado mundial e, com isso, o caráter internacional do regime capitalista. Com a diminuição constante do número dos magnatas do capital, os quais usurpam e monopolizam todas as vantagens desse processo de transformação, aumenta a extensão da miséria, da opressão, da servidão, da degeneração, da exploração, mas também a revolta da classe trabalhadora, sempre numerosa, educada, unida e organizada pelo próprio mecanismo do processo de produção capitalista. $\mathrm{O}$ monopólio do capital torna-se um entrave para o modo de produção que floresceu com ele e sob ele. A centralização dos meios de produção e a socialização do trabalho atingem um ponto em que se tornam incompatíveis com seu invólucro capitalista. Ele é arrebentado. Soa a hora final da propriedade privada capitalista. Os expropriadores são expropriados.

O desenvolvimento das forças produtivas no modo de produção capitalista se dá, assim, segundo sua dupla natureza. Por um lado, segue sendo um meio de oprimir a classe trabalhadora e de extrair do trabalhador o máximo de trabalho

\footnotetext{
1o Bernal (1939, p. 346) coloca que uma vez que o desenvolvimento científico permite a mensuração quantitativa de determinadas necessidades humanas, estas podem ser supridas de formas mais eficientes. O autor cita o exemplo da capacidade de determinar um mínimo e um ótimo da quantidade de nutrientes necessários por uma pessoa, e de como essa capacidade de mensuração possibilita que a distribuição de alimentos seja efetuada tendo esses requerimentos como base.
} 
possível, por outro cria uma massa proletária mundial e um conhecimento técnico científico que entram em contradição com a forma privada da apropriação por uma classe cada vez mais reduzida. Tanto o desenvolvimento do conhecimento como a produção aprofundam seu caráter social e global e a propriedade privada torna-se um empecilho a ambos. No entanto, como salienta Marx (2006, p. 48), para que novas e superiores relações sociais de produção possam tomar o lugar das antigas, sua condição material de existência deve já estar gestada "no próprio seio da velha sociedade”. Não é, portanto, aquilo que o modo de produção capitalista destrói ou supera que pode tomar seu lugar, mas sim aquilo que ele cria. Dessa forma, torna-se importante a investigação acerca das possibilidades de organização da produção, distribuição e cooperação que algumas tecnologias modernas inauguram. Conjuntamente a isso, aponta-se para a necessidade de aproximação da classe proletária e de seus movimentos organizados, dos trabalhadores desses setores modernos.

\section{Novas Tecnologias e Novas Possibilidades de Organização Social}

Como enfatizado por Marx, as forças produtivas e as relações sociais de produção que nela se baseiam e permitem uma nova organização social nascem, ainda que de forma embrionária, no seio da antiga sociedade. No entanto, essas novas forças produtivas mantêm sua dupla natureza, a qual só pode ser resolvida no processo da revolução social. Analisar, portanto, as potencialidades inauguradas por certas novas tecnologias e formas de organização da produção, além das disputas que se estabelecem pelo controle delas, é de grande importância. Dessa forma, será exposto o funcionamento das formas $\mathrm{P}_{2} \mathrm{P}$ de produção e distribuição colaborativa, possibilitado pelos avanços dos computadores pessoais e da internet, além da capacidade de transformação dessa produção virtual em produção material ou, segundo Anderson (2012), da transformação de bits em átomos, inaugurado pelas impressoras e scanners $3 \mathrm{D}$.

O início das formas colaborativas de produção de softwares e do compartilhamento do conhecimento gerado coincide com a ascensão do mercado de computadores pessoais nas décadas de 1960 e 1970 (DAFERMOS, 2008, p. 59). O próprio desenvolvimento dessa nova tecnologia dependia de tal compartilhamento, de forma que até meados desse período os códigos-fonte ${ }^{11}$ eram abertos e compartilhados dentro da pequena comunidade de desenvolvedores de softwares

\footnotetext{
${ }^{11}$ Segundo Rigi (2013, p. 398): "Source code in software consists of human readable algorithms written in a programming language such as Python, Java, C, etc. Source code is translated into machine code (binaries), which computers can read and execute. It is extremely difficult, and indeed next to impossible, to modify, customize or add new features to a program without having the source code. Source code cannot be extracted from binaries, and therefore access to it is necessary in order to make any change in a program."
} 
(RIGI, 2013, p. 399). Esse cenário passa a mudar conforme evolui o mercado e a comercialização de programas e softwares, com os códigos-fonte se tornando verdadeiros segredos industriais. Desde então o desenvolvimento da produção nesse setor vem sendo marcado pelas disputas entre a produção livre e compartilhada e as tentativas de controle e apropriação privada.

A produção compartilhada (peer production, $\mathrm{PP}, \mathrm{P} 2 \mathrm{P}$ ), apesar de apresentar uma evolução contínua, foi marcada por dois momentos definidores (RIGI, 2013, p. 398): o primeiro deles em 1984, quando Richard Stallman criou a GPL (general public license) sob a qual foi lançado o projeto GNU, que abrange um sistema operacional e inúmeros softwares livres; e o segundo em 1991, quando Linus Torvald inventou um sistema de cooperação voluntária on-line para o desenvolvimento do sistema operacional Linux. Para Rigi (2013, p. 398), a invenção de Stallman equivale à forma de propriedade da produção $\mathrm{P}_{2} \mathrm{P}$, enquanto a de Torvald a seu modo de cooperação.

Um software livre é definido por Stallman (1998) como contendo as seguintes características: liberdade para executar o programa como quiser e para qualquer finalidade; liberdade de modificar o programa para atender às suas necessidades (o que requer acesso ao código-fonte); liberdade de redistribuir cópias, seja gratuitamente ou por uma taxa; e liberdade de distribuir versões modificadas do programa. Com o desenvolvimento do sistema operacional GNU, Stallman se deparou com o problema de mantê-lo como software livre e impedir sua apropriação privada, ou a de suas variantes. A solução encontrada foi a criação de uma licença de lançamento que oferecesse essas garantias, conhecida como GPL ${ }^{12}$. Essa licença fornece as quatro garantias que caracterizam um software livre e adiciona uma cláusula, chamada de copyleft, a qual obriga que todo código derivado de outro licenciado sob os termos da GPL, deva também ser lançado sob tal licença. Dessa forma, o software permanece aberto como um todo, e caso o programador adicione códigos fechados a um software livre, estes devem mudar sua licença e tornarem-se abertos para que o acesso ao software permaneça completamente livre. Essa forma de utilização e modificação que se iniciou na área de softwares também chegou à de hardwares livres, em que os projetos são abertos e sua modificação e utilização liberada aos seus usuários. Um exemplo destes é a plataforma aberta de prototipagem eletrônica Arduino ${ }^{13}$, amplamente utilizada pelos desenvolvedores de projetos compartilhados.

\footnotetext{
${ }_{12}$ Tanto o projeto GNU como o GNU/LINUX foram lançados sob essa licença, o que faz dela a mais utilizada nos projetos de softwares livres.

13 De acordo com Anderson (2012, p, 38), esse tipo de plataforma tem a seguinte função: "It allows anyone to connect computing and the physical world, by making it easy to attach sensors and actuators to a computer program. This is often called "physical computing" or "embedded computing," and you see examples of it all around you. Practically every electronic device in your home works this way, from your thermostat to your alarm clocks, stereos, microwave oven, and portable music players. Your car has dozens of embedded computers. The difference is that they are all closed and proprietary, while
} 
$\mathrm{O}$ segundo passo no desenvolvimento da produção $\mathrm{P}_{2} \mathrm{P}$ foi dado por Linus Torvald, com o desenvolvimento de uma rede de cooperação on-line, livre e aberta. Para Bauwens (2003, p. 20), o desenvolvimento dessa forma $\mathrm{P}_{2} \mathrm{P}$ representa $\mathrm{o}$ casamento do mundo da internet com o mundo dos computadores pessoais, e tem a capacidade de gerar uma rede global livre de troca e compartilhamento do conhecimento e da produção. Foi essa potencialidade que Torvald colocou em ação para o desenvolvimento do sistema operacional Linux, quando em 1991 ele disponibilizou na rede o código kernel $^{14}$ do programa e convidou qualquer interessado a participar do projeto. O desenvolvimento de um sistema operacional é algo bastante complicado, segundo o site informationisbeautiful.net ${ }^{15}$, apenas o código Kernel da versão 2.6.o do Linux possui cerca de 5 milhões de linhas, o sistema operacional completo Linux 3.1 cerca de 15 milhões, o Windows XP aproximadamente 40 milhões e o pacote Microsoft Office 2013 possui 50 milhões de linhas de código. Ao disponibilizar o Kernel do Linux em outubro de 1991, o qual foi baseado no GNU e lançado sob a licença GPL, formou-se uma rede de colaboradores que tornou possível o lançamento da primeira versão do sistema operacional em março de 1994. Segundo Dafermos (2008, p. 62), a versão 2.6.24 do programa contou com 1.057 colaboradores individuais e 186 empresas, sendo que os primeiros respondem por cerca de $27 \%$ das mudanças. Mais importante que a quantidade de colaboradores, no entanto, é a forma dessa colaboração e do processo de trabalho que se estabelece. De acordo com Dafermos (2008, p. 54):

In our view, the joy of participating in FOSS (free software and open source software) projects should be seen against the backdrop of alienated work relations. Hackers gear their labour power towards the use value of the software as opposed to its exchange value: free software is produced to be used, not to be sold. In FOSS projects, work is an end in itself rather than a means for something else. That is the deeper meaning of the common expression among hackers that they write code just to 'scratch their itch'. In attempting to escape from alienated existence, the hacker movement has invented an alternative model

Arduino is designed to be easy for anyone to use and modify. Much of the emerging "Internet of Things" movement is built on Arduino- based devices connected to the Web, from coffeemakers that tweet their status to pet feeders you can control from your phone, wherever you are.

14 O Kernel é o núcleo de um sistema operacional e responsável pela interação entre o hardware e o software de um computador. "Basicamente, ele começa a funcionar assim que o computador é ligado; nesse momento ele inicia a detecção de todo o hardware indispensável ao funcionamento da máquina (monitor, placa de vídeo etc.). O Sistema Operacional é carregado em seguida e, uma vez que o usuário faça seu login, o Kernel passa a administrar as principais funções dentro do S.O: isso inclui o gerenciamento da memória, dos processos, dos arquivos e de todos os dispositivos periféricos. Dessa forma o Kernel pode ser descrito como um grande organizador: é ele o responsável por garantir que todos os programas terão acesso aos recursos de que necessitam (memória RAM, por exemplo) simultaneamente, fazendo com que haja um compartilhamento concorrente - mas sem oferecer riscos à integridade da máquina" (AMARAL, 2009).

${ }_{15}$ Disponível em: http://www.informationisbeautiful.net/visualizations/million-lines-of-code/. 
for organizing labour founded on the common ownership of the means of production, on volunteer participation and the principle of self-expression in work.

Dentro desse sistema cooperativo de trabalho não existe uma divisão centralizada das tarefas, cada colaborador escolhe a área na qual deseja atuar e o tempo de trabalho dedicado a ela. As soluções são publicadas e discutidas em grupo, e a incorporação dos resultados é decidida dessa forma. Caso alguma alteração não seja aceita nada impede que seu proponente tome o código todo e o desenvolva na direção de sua preferência (RIGI, 2013, p. 401). Por fim o produto final fica livremente ${ }^{16}$ disponível tanto para seus produtores quanto para os consumidores que o desejarem. A internet possibilita, por sua vez, que essa forma de cooperação seja global e completamente desterritorializada, de forma que mesmo as barreiras ao local de trabalho são gradativamente superadas. Essa forma de cooperação que se iniciou na criação do sistema operacional Linux já se espraiou para outras áreas, e com o desenvolvimento das impressoras $3 \mathrm{D}$ e incorporação de softwares nos mais variados objetos e produtos, já atinge a própria produção material. A forma de cooperação pode mudar de projeto para projeto e dar espaço para a apropriação privada do conhecimento e do trabalho compartilhado, no entanto suas potencialidades e utilização crescem nas mais variadas áreas.

Anderson (2012) cita em seu livro o exemplo de duas experiências na produção compartilhada de produtos físicos, a primeira na área de irrigadores residenciais controlados pela internet e a segunda de drones com sistema de piloto automático. Em ambos o autor iniciou o processo de desenvolvimento montando uma rede social aberta com o objetivo de discutir os projetos, e rapidamente uma série de interessados se juntaram a ele. Os colaboradores do projeto tinham em grande parte carreiras muito distintas, e sua colaboração se movia muito mais por interesse no assunto do que por alguma forma de recompensa imediata. As discussões e aperfeiçoamentos no projeto eram feitas em comunidade, da qual participavam pessoas de inúmeras partes do globo, os protótipos eram feitos em impressoras $3 \mathrm{D}$ ou equipamentos similares, especialmente em oficinas que ofereciam esses serviços de impressão, e o produto final ficava disponível para aquele que o quisesse produzir. Segundo o autor, o projeto do drone se transformou em uma empresa comercial, no entanto ele segue aberto e drones similares, com o mesmo sistema de controle, e já são produzidos em outros locais.

Essa forma compartilhada de produção de objetos e equipamentos ainda se encontra em seus passos iniciais. No entanto, a criação de softwares livres CAD (computer aided design), de projetos livres de impressoras e scanners $3 \mathrm{D}$, máquinas CNC (computer numerical control) e cortadores laser, além do surgimento disperso de oficinas que oferecem esse tipo de impressão em pequena ou larga escala, têm

\footnotetext{
${ }^{16}$ Como explica Stallman (1998), livre remete às quatro liberdades que caracterizam um software aberto e não necessariamente à gratuidade do programa.
} 
impulsionado essa forma $\mathrm{P}_{2} \mathrm{P}$ de produção. Resumidamente a produção de um objeto através dessas ferramentas é feito da seguinte maneira: Primeiro o objeto é desenhado a partir do zero em um programa CAD, ou transmitido a ele através de um scanner $3 \mathrm{D}$ e posteriormente modificado. O processo de escaneamento depende da complexidade do objeto, no qual os mais simples podem ser feitos a partir de uma série de fotos em vários ângulos com a câmera de um celular. No CAD o objeto não apenas é desenhado, mas também se determina seu material, consistência, flexibilidade, capacidade de conduzir eletricidade, etc. de forma que essas especificações e desenhos são transformados em equações que irão instruir a máquina que irá imprimi-lo (ANDERSON, 2012, p. 75). As impressoras 3 3 (adição), máquinas $\mathrm{CNC}$ (subtração) ou cortadores laser (corte em $2 \mathrm{D}$ ), interpretam essas equações e as transformam em movimento. O software de uma impressora $3 \mathrm{D}$, por exemplo, examina o arquivo CAD e transforma-o em comandos para a impressora de forma a utilizar o mínimo de material e atingir todas as especificações do produto. As impressoras mais simples são compostas de quatro motores, sendo que dois movem a cabeça do injetor nos eixos $\mathrm{x}$ e y e um terceiro move a plataforma de impressão para baixo, o quarto motor transporta a substância plástica para um aquecedor e posteriormente para o injetor. Quanto menor o movimento da plataforma, maior a quantidade de camadas e melhor a resolução do objeto. Outras impressoras $3 \mathrm{D}$ também funcionam com um laser que endurece uma resina líquida ou em pó e utilizam os mais variados materiais, criando desde peças sólidas, circuitos elétricos, até materiais orgânicos ${ }^{17}$.

As transformações possibilitadas por essas novas tecnologias e formas de cooperação não se limitam, no entanto, à produção, mas também inauguram uma nova forma de distribuição. Existem inúmeros softwares que permitem o envio e recebimento de arquivos e programas que ficam armazenados em computadores pessoais, os quais são automaticamente transferidos quando solicitados, desde que permitido pelo computador hospedeiro (host). Em grande medida essa forma de distribuição supera a forma inicial de distribuição na internet, caracterizada pela relação cliente-servidor. Segundo Bauwens (2003, p. 18), essa relação impunha restrições para o conteúdo que podia ser postado e acessado na rede, "ordinary PC users who wanted to post content or services needed access to a server, which created inequality in access, but with true peer to peer file sharing technologies, any PC user is enabled to do this." Na produção através de impressoras 3D e similares,

\footnotetext{
${ }_{17}$ Segundo Anderson (2012, p. 82): "Some 3-D printers extrude molten plastic in layers to make these objects, while others use a laser to harden layers of liquid or powder resin so the product emerges from a bath of the raw material. Yet others can make objects out of any material from glass, steel, and bronze to gold, titanium, or even cake frosting. You can print a flute or you can print a meal. You can even print human organs out of living cells, by squirting a fluid with suspended stem cells onto a support matrix, much as your inkjet printer squirts ink onto paper."
} 
por sua vez, a separação entre produção e distribuição é praticamente eliminada, uma vez que ambos os processos ocorrem simultaneamente. Obviamente os insumos e as matérias-primas utilizados por esses equipamentos ainda dependem de outros meios de distribuição, mas ainda vivenciamos aqui os passos iniciais dessas tecnologias e de seus encadeamentos nos demais setores.

Os processos de trabalho, produção e distribuição proporcionados por essas tecnologias diferem em muito dos processos dominantes dentro do modo de produção capitalista. Para Rigi (2013, p. 402-404), essa produção e distribuição colaborativa assemelham-se em inúmeras formas da descrição de Marx sobre o modo de produção no comunismo avançado. Em primeiro lugar, o autor percebe que em ambos está ausente a lógica de equivalência, de forma que o produtor ou o consumidor não retiram uma quantidade do produto equivalente à sua colaboração ou ao seu trabalho, mas esse encontra-se disponível amplamente, independente da contribuição. O segundo ponto é a negação da alienação, uma vez que no sistema $\mathrm{P}_{2} \mathrm{P}$ se transcende a divisão do trabalho capitalista e este se aproxima de uma atividade prazerosa e criativa. O terceiro aspecto é que o processo de trabalho na produção colaborativa supera o sistema hierárquico e a fixação do trabalhador em uma atividade e local específicos. Existe liberdade no tempo de trabalho dedicado e na área de atuação, as necessidades mais urgentes são definidas coletivamente assim como as decisões são amplamente discutidas, formando-se assim um processo amplo de democracia da produção. Outro aspecto importante da produção e distribuição colaborativa é que dentro dela o meio de produção deixa de estar separado do produtor, como no caso dos computadores e impressoras $3 \mathrm{D}$ pessoais.

Apesar das potencialidades de novas formas de organização do trabalho, da produção e da distribuição, inaugurada por essas tecnologias, elas ainda se dão dentro do modo de produção capitalista e estão sujeitas à sua relação de propriedade. Em grande medida, os participantes de projetos $\mathrm{P}_{2} \mathrm{P}$ mantém empregos fixos em empresas privadas e dependem destes para sua subsistência. Os softwares livres são amplamente utilizados pelo capital privado e servem como um meio de redução de custos, além de possibilitarem maior controle e racionalização da produção e ainda aumento na intensidade do trabalho. No entanto, mais importante e talvez menos perceptível é a busca pelo controle privado dessa forma compartilhada de produção e distribuição. Peter Sande, um dos fundadores do site thepiratebay, o qual se tornou o maior site de compartilhamento de arquivos do mundo, faz o seguinte relato em uma entrevista a Joost Mollen (2015):

Well, we don't have an open internet. We haven't had an open internet for a long time. So, we can't really talk about the open internet because it does not exist anymore. The problem is nobody stops anything. We are losing privileges and rights all of the time. We are not gaining anything anywhere. The trend is just going in one direction: a more closed and more controlled internet. That has a big impact on our society [...]. 
Just by being a virtual thing, it's suddenly not directed at you. You don't see someone spying on you, you don't see something censored, you don't see it when someone deletes stuff out of the search results out of Google. I think that's the biggest problem to get people's attention. You don't see the problems, so people don't feel connected to it [...].

Well, the thing is the internet is really stupid. It works really simply in a simple manner and it doesn't take any adjustments for censorship. Like, if one cable is gone, you take the traffic through some other place. But thanks to the centralization of the internet, (possible) censorship or surveillance tech is a whole lot harder to get around. Also, because the internet was an American invention, they also still have control of it and ICANN can actually force any country top level domain to be censored or disconnected. For me that's, a really broken design.

Um exemplo importante de controle sobre o compartilhamento on-line são as tecnologias DRM (digital right management), incorporadas em arquivos de música, vídeo, jogos e programas. Essas tecnologias permitem a restrição na forma de utilização desses arquivos, podendo limitar a quantidade de cópias, instalações, compartilhamentos ou mesmo vinculando o arquivo a uma conta específica. Segundo Ramos Junior (2009), empresas como a Microsoft utilizam amplamente essa tecnologia. O Windows Media, por exemplo, possui um verificador de direito de uso que permite apenas a execução de arquivos registrados e impede que os arquivos baixados através desse programa sejam utilizados em outro lugar; esse mecanismo funciona "como se fosse um muro: nada entra e nada sai". Existem softwares capazes de burlar esses controles, chamados de jailbrakers, no entanto sua utilização esbarra em questões legais de direito de propriedade.

Nesse aspecto pode-se perceber uma grande contradição entre essas novas forças produtivas e as relações de produção que se ensaiam, e a forma jurídica de propriedade que expressa as relações sociais de produção capitalistas. Outro fator importante a ser considerado é que a economia digital ainda representa uma parcela muito inferior em comparação à economia "beyond the Web" (ANDERSON, 2012, p. 9). Estima-se que as receitas da primeira se aproximem dos US\$ 20 trilhões, sendo que a produção $\mathrm{P}_{2} \mathrm{P}$ responde por uma parcela diminuta desse total, enquanto as da segunda alcançam o patamar de US\$ 130 trilhões ${ }^{18}$. No entanto, apesar dessa diferença de magnitude e da busca pelo controle e pela apropriação privada dessa forma de produção e distribuição, em muitos aspectos a forma $\mathrm{P}_{2} \mathrm{P}$ apresenta maior produtividade que as tradicionais. Bauwens (2003, p. 24), considerando essa maior produtividade, faz o seguinte questionamento:

This situation leads to a interesting and first historical analogy: when capitalist methods of production emerged, the feudal system, the guilds and the craftsmen at first tried to oppose and stop them (up to the physical liquidation of machines by the Luddites in the UK), but they largely failed. It is not difficult to see a comparison with the struggle of the RIAA

\footnotetext{
${ }^{18}$ Essas estimativas são citadas por Anderson (2012, p. 9) a partir de estudos do Citibank e Oxford economics. Disponíveis em: http://www.citibank.com/transactionservices/home/docs/the_new_digital_economy.pdf.
} 
(Recording Industry Association of America) against Napster: they may have won legally, but the phenomenon is continuing to spread. In general, we can interpret many of the current conflicts as pitting against each other the old way of production, commodity based production and its legal infrastructure of copyright, and the new technological and social practices undermining these existing processes. In the short term, the forces of the old try to increase their hold and faced with subverting influences, strengthen the legal and the repressive apparatus. But in the long term the question is: can they hold back these more productive processes?

Essa questão da maior produtividade na produção $\mathrm{P}_{2} \mathrm{P}$ é de grande importância. A lógica concorrencial no modo de produção capitalista impõe a necessidade constante ao capitalista individual de implantar meios mais eficientes de realizar a produção. Essa ação individual pode gerar, no entanto, efeitos contrários do ponto de vista do capital total e da classe capitalista; um exemplo disso é o desenvolvimento de Marx a respeito da queda tendencial da taxa de lucro. Mesmo assim, a sobrevivência do capitalista individual depende desse tipo de atitude. A maior produtividade das formas $\mathrm{P}_{2} \mathrm{P}$ de produção e distribuição é o fator chave de sua sobrevivência e de seu aprofundamento. O efeito disso pode ser visto na própria promoção de empresas privadas para que seus empregados se dediquem a projetos compartilhados de softwares livres. Segundo Dafermos (2008, p.64), um estudo com 287 projetos de softwares livres averiguou que $40 \%$ dos contribuintes eram pagos por empresas privadas e incentivados a dedicar horas de seu trabalho no escritório a esses projetos.

Os apontamentos feitos até aqui levantam importantes questões sobre as potencialidades inauguradas por essas novas tecnologias, as quais permitem, mesmo que de forma embrionária, uma organização distinta da produção, distribuição e cooperação. No entanto, apenas a existência dessas forças produtivas não é suficiente para uma transformação mais profunda da sociedade. Como salienta Marx, a segunda condição é a existência de uma massa revolucionária capaz de promover tal mudança, levando à superação das barreiras que impedem que as novas forças produtivas e as novas relações sociais de produção se desenvolvam de acordo uma com a outra. Essa questão é exposta por Rigi (2013, p. 412) da seguinte maneira:

[T] he victory of PP cannot be taken for granted. Capitalism will not collapse of its own accord. Everything will depend on social and political struggles, of which the expansion of $\mathrm{PP}$ is an important component. The final victory of $\mathrm{PP}$, if it is to happen at all, will not be merely a result of the gradual expansion of the PP mode of production. It will also depend on social revolutions that abolish the private ownership of strategic natural resources and major infrastructure, and transform them into shared commons of humanity. Without such commons, PP will not become the dominant mode of production. Without such social revolutions, capitalism may succeed in subduing the threat posed by PP. State and corporate empires will fight tooth and nail to bring IT technologies under their full control, as they did with previous transformative technologies such as the radio. 
A novidade dessas tecnologias, a restrição ao acesso a elas por grande parte da massa trabalhadora, e o fato de que em geral os trabalhadores dessas áreas pertencem a uma camada mais elevada dessa classe, são fatores que jogam contra uma aliança mais ampla em relação às lutas da classe trabalhadora. Mesmo dentro da comunidade de hackers ${ }^{19}$, encontram-se as mais variadas ideologias e ainda estão iniciando-se os movimentos organizados mais combativos. No entanto, a defesa pela produção colaborativa e contra sua apropriação e seu controle privado e a luta por uma internet mais livre e abrangente são pautas importantes a serem incorporadas pelos movimentos mais tradicionais dos trabalhadores. Ao mesmo tempo, a organização em rede da comunidade hacker e o uso das ferramentas de comunicação e compartilhamento utilizadas por eles, podem servir como importantes instrumentos e exemplos a serem incorporados na forma de organização e atuação da luta da classe operária.

\section{Conclusão}

O desenvolvimento das forças produtivas no modo de produção capitalista é marcado pelo duplo movimento de afirmação e contradição com as relações sociais de produção dominantes. A exposição acima não busca inferir que, apenas recentemente, com o desenvolvimento dessas novas tecnologias, é que tal contradição passa a operar. Esta se verifica na medida em que as forças produtivas no modo de produção capitalista se baseiam na extensa divisão e socialização da produção e do conhecimento, no caráter mundial da produção e distribuição e na formação de uma classe operária global, de modo que todo o processo de desenvolvimento da moderna fábrica mecanizada contém em si esse duplo movimento de afirmação e contradição. A importância verificada em relação às novas tecnologias tratadas se dá, no entanto, no fato de que não apenas estas se inserem nesse movimento contraditório, como também inauguram novas formas sociais de produção, distribuição, cooperação e mesmo de relações de propriedade. Outro fator importante é que essas novas tecnologias não se inserem de forma marginal no modo de produção capitalista, mas se apresentam como formas altamente produtivas e na vanguarda do desenvolvimento tecnológico.

Essas potencialidades inauguradas pelas novas forças produtivas não significam, no entanto, que as relações sociais de produção possibilitadas por elas irão inevitavelmente se realizar. Como essas se desenvolvem dentro do modo de produção capitalista ainda guardam uma relação estreita com ele, de maneira que

\footnotetext{
19 Segundo Stallman (1998), “o uso do termo 'hacker' significando 'violador de segurança' é uma confusão por parte dos meios de comunicação de massa. Nós hackers nos recusamos a reconhecer este significado, e continuamos usando a palavra com o significado de alguém que ama programar, alguém que aprecia brincadeiras inteligentes, ou a combinação dos dois."
} 
também são utilizadas como ferramentas para a valorização do capital. Este, portanto, busca das mais variadas formas exercer seu controle sobre tal desenvolvimento e manter sua forma de apropriação privada. Apenas o resultado da luta de classes pode agir decisivamente sobre a realização ou não das potencialidades que se ensaiam. Dessa forma, se dá a importância de aproximação dos movimentos organizados em relação a essas pautas, e dos trabalhadores desses setores mais modernos em relação à classe trabalhadora em geral.

\section{Referências}

AMARAL, E. F. O Que é Kernel? 2009. Disponível em:

http://www.tecmundo.com.br/mac-os-x/1636-o-que-e-kernel-.htm. Acesso em: 7 jan., 2016.

ANDERSON, C. Makers: The New Industrial Revolution. New York: Crown Business, 2012.

BAUWENS, M. Peer to peer: From technology to politics to a new civilization? Journal of Philosophy and Religion, Bangkok, v. 4, n. 2, p. 18-52. 2003.

BERNAL, J. D. The Social Function of Science. London: George Routledge and Sons, 1939 .

BRYER, R. Accounting and control of the labour process. Critical Perspectives on Accounting, Warwick, n. 17, p. 551-598, 2006. DOI:

https://doi.org/10.1016/j.cpa.2003.06.010

BURNS, T. Industrial Man. Harmondsworth: Penguin, 1969.

CHANDLER, A. D. Jr. The Visible Hand. Massachusetts: Harvard University Press, 1977 .

DAFERMOS, G.; SODERBERG, J. The hacker movement as a continuation of labour struggle. Capital \& Class, Limerick, v. 33, n. 1, p. 53-73, spring 2009. DOI: https://doi.org/10.1177/030981680909700104

GERMER, C. M. Marx e o papel determinante das forças produtivas na evolução social. Crítica Marxista, Campinas, n. 29, p. 75-95, 2009.

HANSEN, A. H. The technological interpretation of History. Quarterly Journal of Economics, p. 72-83. 1921. https://doi.org/10.2307/1883779

HEILBRONER, R. L. Do machines make history? Technology and Culture, Baltimore, v. 8, n. 3, p. 335-345. 1967. https://doi.org/10.2307/3101719

HEILBRONER, R. L. Technological Determinism Revisited. In: SMITH, M. Does Technology Drive History? London: MIT Press, p. 67-78. 1998. 
KOSIK, K. A Dialética do Concreto. São Paulo: Paz e Terra, 2011.

LANDES, D. S. Prometeu Desacorrentado. São Paulo: Campus, 2005.

LUKÁCS, G. Technology and social relations. New Left Review, London, I/39, p. 27-34, set-out. 1966.

MACKENZIE, D. Marx and the machine. Technology and Culture, Baltimore, v. 25, n. 3, p. 473-502, Jul. 1984. https://doi.org/10.2307/3104202

MARX, K. Contribuição à Crítica da Economia Política. São Paulo: Expressão Popular, 2008.

MARX, K. O 18 de Brumário de Luís Bonaparte. São Paulo: Boitempo, 2011.

MARX, K. O Capital. São Paulo: Nova Cultural, (Os Economistas). Livro I, Tomo I. 1996.

MARX, K.; ENGELS, F. A Ideologia Alemã. São Paulo: Martin Claret, 2006.

MOLLEN, J. Pirate Bay Founder: 'I Have Given Up'. 2015. Disponível em: http://motherboard.vice.com/read/pirate-bay-founder-peter-sunde-i-have-givenup. Acesso em: 7 jan. 2016.

RIGI, J. Peer production and Marxian communism: contours of a new emerging mode of production. Capital \& Class, Limerick, v. 37, n. 3, p. 397-416, out. 2013. DOI: https://doi.org/10.1177/0309816813503979

ROSEnBERG, N. Por Dentro da Caixa-Preta. Campinas: Unicamp, 2006.

SHAIKH, A. Valor, Acumulación y Crisis: Ensayos de Economía Política. Bogotá: Tercer Mundo Editores, 1991.

STALLMAN, R. O Projeto GNU. 1998. Disponível em: http://www.gnu.org/gnu/thegnuproject.html. Acesso em: 10 dez. 2015.

STEINBECK, J. As Vinhas da Ira. São Paulo: Círculo do Livro, 1966.

THE Great Dictator. Direção de Charles Chaplin. Roteiro: Charles Chaplin. New York: Charles Chaplin Film Corporation, 1940. 